\title{
Validation and Transcultural Adaptation of Hemangiomas Severity Scale
}

Laura Mariel González-Cárdenas ${ }^{1 *}$ MD, Gloria María Rosales-Solís ${ }^{1}$ MD, Erika Lizbeth Alba Rojas ${ }^{2}$ MD, Manuel Enrique de la O-Cavazos ${ }^{1}$ MD, Dariela Errisuris-Olvera ${ }^{1}$ MD, Itzel Zavala-Ramos ${ }^{1}$ MD.

${ }^{1}$ Department of Pediatrics, University Hospital "Dr. José Eleuterio González", Universidad Autonoma de Nuevo Leon (U.A.N.L.), Monterrey, Nuevo Leon, Mexico.

${ }^{2}$ Department of Dermatology, University Hospital "Dr. José Eleuterio González",Universidad Autonoma de Nuevo Leon (U.A.N.L.), Monterrey, Nuevo Leon, Mexico.

*Corresponding Author: Laura Mariel González-Cárdenas M.D, Department of Pediatrics, University Hospital "Dr. José Eleuterio González" Universidad Autonoma de Nuevo Leon (U.A.N.L.) Ave. Francisco I. Madero and Ave. Gonzalitos s/n, Col. Mitras Centro, C.P. 64460 Monterrey, Nuevo León, Mexico.

Received date: June 11, 2020; Accepted date: June 23, 2020; Published date: June 27, 2020

Citation: Laura C, Gloria M, Erika L, Manuel E, Dariela E, et al. (2020). Validation and Transcultural Adaptation of Hemangiomas Severity Scale. J Dermatology and Dermatitis.5 (2); Doi: 10.31579/2578-8949/68

Copyright: (C2020 Laura Mariel González-Cárdenas, This is an open-access article distributed under the terms of The Creative Commons. Attribution License, which permits unrestricted use, distribution, and reproduction in any medium, provided the original author and source are credited.

\section{Abstract}

Introduction: Infantile hemangiomas are the most common benign soft tissue tumors in pediatrics, with a general incidence of $3-10 \%$ of the population. The Hemangioma Severity Scale was formulated by Haggstrom et al 2012, to measure the severity of hemangiomas according to the identification of clinical variables, assigning morbidity values associated with already published variables and in the clinical experience of experts on the subject. However, it has been designed and developed in the American population. Therefore, the objective of this study was to validate and translate the Hemangioma Severity Scale for its application in Mexican pediatric patients.

Materials and methods: The hemangioma severity scale was applied by 2 expert pediatric dermatology subspecialists, and then the responses were compared using correlation indices by a statistician who was biased.

Results: A coefficient was performed on the first item, an index of 0.714 was obtained. The following items obtained a 0.799 for the location, a 1 for the risk of structural abnormalities, 0.516 for complications, 0.298 for the item of pain and in the general risk and probability of deformation a kappa index of 0.670 was obtained.

Conclusions: The application of the Hemangiomas Severity Scale in pediatric patients is a useful and reproducible tool with great clinical applicability in our population.

Key words: childhood; hemangioma severity scale; infantile hemangiomas; mexican population; pediatrics

\section{Introduction}

Infantile hemangiomas $(\mathrm{IH})$ are the most common benign soft tissue tumors in pediatrics, with a general incidence of $3-10 \%$ of the general population [1,2]. Despite being a widely used term in medicine, the concept of hemangioma is confusing. The term is commonly used to name different types of vascular type tumors as well as vascular malformations [3]. In 1996 the International Society for the Study of Vascular Abnormalities (ISSVA) classified abnormalities in malformations and proliferative vascular lesions. This classification was unofficially adopted. And updated in recent years [3]. There are various predisposing risk factors such as female sex, preterm products, low weight, multiple pregnancies, advanced maternal age, and placental abnormalities. These lesions are not observed at birth, they are usually diagnosed at 4-6 weeks of life with a maximum growth peak at 5 months of age with progressive involution $[1,4]$.

Approximately $12 \%$ of hemangiomas present complications, requiring the evaluation of a specialist, leaving permanent sequelae in some cases [5]. Severe cases that require specialized therapy include those lesions that due to their location or distribution can be life-threatening (subglottic, multifocal with visceral involvement), jeopardize function (peri-orifices), cause ulcerations or bleeding (lumbosacral or genital) or are at risk of (facial) disfigurement [6].
Historically, treatment for IH consisted of systemic therapy with glucocorticoids, interferon alfa, and vincristine, but the efficacy of the treatment was variable and the safety of drugs in childhood was not fully understood [7]. Starting in 2008, the use of propanolol began effectively, considering it as a first-line treatment for IH. [6] Several scales have been developed to determine the severity of hemangiomas. The Hemangioma Severity Scale (HSS) was formulated by a multi-institutional group made up of 14 pediatric dermatologists and 1 hemato-oncologist at 9 academic medical centers in the United States [1]. Creating a scale that measures the severity of hemangiomas according to the identification of clinical variables, assigning morbidity values associated with already published variables and in the clinical experience of experts on the subject [8]. This scale was validated for the US population and was applied in 20 patients by 15 evaluators and consists of the following points: Size, location, risk of associated structural abnormalities, complications, pain, risk / probability of disfigurement in the face-ear, risk / probability of disfigurement in areas outside the ear [1]

The use of scales is important because they allow obtaining results to support clinical decisions about a patient's disease, understanding a phenomenon and knowing its behavior $[9,10]$. In Mexico, there is no scale that appropriately evaluated the severity of hemangiomas. It is usually reserved for the clinical experience of the treating physician and with the use of scales not validated in our context and culture. Therefore, the 
objective of this study is to validate and translate the HSS for application in national pediatric patients.

\section{Materials and methods}

Cross-sectional study with a descriptive, observational and crosssectional design in which 20 patients were included, who attended the pediatric consultation and the diagnosis of hemangioma was made at the University Hospital "Dr. José E. González" from UANL for evaluation, as well as validation and translation of the HSS.

The inclusion criteria used in this study were: Pediatric patients between 0 to 6 years old, patients with a diagnosis of Infantile hemangioma and those who agreed to participate in the study. The exclusion criteria that were taken into account were: Alteration that modifies the anatomy of the area of the injury, medical or surgical procedures that modify the injuries, having traumatic injuries in the areas of the hemangioma, that the patient does not agree to participate in the study and patients too restless who did not allow taking the photograph.

The elimination criteria were: voluntary withdrawal of the patient from the study by the parents and diagnosis of some other pathology that required immediate evaluation.

The sample was calculated based on the recommendations of the World Health Organization for the process of validation and translation of instruments in medicine. A minimum of 10 patients was considered recommended for each section used in the surveys. Therefore, 20 patients were included in the evaluation because two sections were included. The sample was obtained for convenience without being randomized in sequential cases.

The hemangioma severity scale was translated from the original language (English) to the Spanish language, spoken in Mexico, by a certified bilingual native translator. After translation, the investigator-in-charge made a summary of the adjustments to be corrected. Relevant corrections were made for the production of the final version of the scale.

The scale was applied and performed by two specialists in pediatric dermatology. It was applied in the presence of the patient for the direct evaluation of hemangiomas. The evaluation was carried out individually by each of the evaluators. There was no communication between the two, during the first time consultation or follow-up of children with the diagnosis of hemangioma. Parents were asked permission to perform the hemangioma severity scale, which consists of identifying the lesion, its location and involvement of structures, as well as taking a measurement with a tape measure to obtain the diameter of the lesion. In addition, they were asked for consent to take a photograph with a professional camera to document the injury to show only the area of the body with the injury without unnecessarily observing areas. It was explained to them that this scale is only to directly assess the injury to the patient, without taking blood or tissue samples, or psychological or invasive tests.

The results were emptied into an Excel table and then analyzed by SPSS version 24. The scores were then compared to assess intraobserver reliability for the final result, as well as for each item. Intra- and interrater reliability was calculated for qualitative observations using the Cohen's kappa The statistical evaluator was blinded. The interpretation of concordance values was adapted as follows: $\mathrm{k}$ less than 0.20 , poor agreement; k of $0.21-0.40$, fair agreement; $\mathrm{k}$ of $0.41-0.60$, moderate agreement; $\mathrm{k}$ of $0.61-0.80$, good agreement; and $\mathrm{k}$ of $0.81-1.00$, very good agreement.

\section{Results}

Two observers scaled a total of 20 patients. The mean age was 16.45 months with a standard deviation of \pm 12.75 months. Sixteen female and four male patients were included, a percentage of 80 and $20 \%$, respectively (Table 1). $45 \%$ of the patients have facial injuries and $55 \%$ presented injuries that were classified as extra-facial.

\begin{tabular}{|l|l|}
\hline Patients $(\mathrm{n}, \%)$ & $20(100)$ \\
\hline Age in months $( \pm \mathrm{DE})$ & $16.45 \pm 12$ \\
\hline Female $(\mathrm{n}, \%)$ & $16(80)$ \\
\hline Male $(\mathrm{n}, \%)$ & $4(20)$ \\
\hline
\end{tabular}

Table 1. Demographic data.

For the evaluation, a kappa coefficient was performed for each item on the scale, a general index was obtained with the 20 patients of 0.714 and for the evaluations of the specific items for facial and extra-facial injuries, a kappa index of 0.654 was obtained and 0.621 respectively. The following items obtained a 0.799 for the location, a 1.0 for the risk of structural anomalies, 0.516 for complications, 0.298 for the item of pain and in the general risk and probability of deformation, a kappa index of 0.670 was obtained, and specifically in this item the breakdown of facial and extra facial was also made, obtaining indices of 0.690 and 0.515 respectively (Table 2).

\begin{tabular}{|c|c|c|c|}
\hline & \multicolumn{3}{|l|}{ Kappa index } \\
\hline 1.-Size (measured in its longest length) & \multicolumn{3}{|l|}{0.714} \\
\hline Facial & \multicolumn{3}{|l|}{0.654} \\
\hline Extra facial & \multicolumn{3}{|l|}{0.621} \\
\hline 2.-Location & \multicolumn{3}{|l|}{0.799} \\
\hline 3.- Risk of Associated Structural Anomalies & \multicolumn{3}{|l|}{1} \\
\hline $\begin{array}{l}\text { 4.- Complications (present at the time of the } \\
\text { exam) }\end{array}$ & \multicolumn{3}{|l|}{0.516} \\
\hline 5.- Pain & \multicolumn{3}{|l|}{0.298} \\
\hline 6.- Risk / Probability of disfigurement & \multicolumn{3}{|l|}{0.670} \\
\hline Facial & \multicolumn{3}{|l|}{0.690} \\
\hline Extra facial & \multicolumn{3}{|l|}{0.515} \\
\hline \multirow{2}{*}{ Total score } & Examiner 1 & Examiner 2 & $p^{*}$ \\
\hline & 7 & 6 & 0.87 \\
\hline
\end{tabular}

* Mann Whitney U Test 
The average score for each examiner was obtained, with examiner 1 obtaining a mean of 7 and examiner 2 of 6 , without statistically significant differences between each examiner (Table 2). In 7 patients the difference was greater than 2 points between the total results obtained by the examiners.

\section{Discussion}

The validation of scales in local language is extremely important due to cultural changes and the adaptation of words, especially from English to Spanish.

In our work, a satisfactory kappa correlation index was observed in most of the items evaluated and perfect in the item of risk of associated structural anomalies, this due to the exact description used in the response items of this item. The item of complications present at the time of the evaluation obtained a moderate agreement, this is probably due to the wide variety of responses.

In the study where this scale was evaluated, there is a wide inter-observer variability of complications, with percentages of agreement that could go from $100 \%$ to $62 \%$ (1). Lastly, the item where pain is evaluated was the one with the most inter-observer variability, this can be explained by the little explanation of these items on the scale, especially with the subsection "none" and "mild intermittent pain that does not require systemic medication" This could be confusing for the scale applicators due to the variability in the ages of the patients evaluated.

In our study, the minimum age studied was 4 months and the maximum was 48 months. In these cases the evaluation of pain is different and erroneous evaluation can be carried out especially with examiners with less clinical experience. No statistically significant differences were observed when comparing the total scores obtained between each examiner, which tells us of a homogeneity of the results.

The weaknesses of our study is the lack of the intraobserver pilot test to be used in pediatric residents, as well as the strengths of our study is that it is the first study to be validated in the Mexican population.

\section{Conclusions}

The application of the Hemangiomas Severity Scale in pediatric patients in our population is a useful and reproducible tool with great clinical applicability, since the evaluation is simple and does not require further extension of the time of a regular consultation in this type of patient.
The revision of the pain assessment is suggested for a better agreement of the results obtained between the examiners in order to obtain more homogeneous results.

\section{Referencias}

1. Haggstrom AN, Beaumont JL, Lai JS, Adams DM, Drolet BA, Frieden IJ, et al. (2012) Measuring the severity of infantile hemangiomas: Instrument development and reliability. Arch Dermatol.148 (2):197-202.

2. Janmohamed SR, De Waard-Van Der Spek FB, Madern GC, De Laat PCJ, Hop WCJ, Oranje AP. (2011) Scoring the proliferative activity of haemangioma of infancy: The Haemangioma Activity Score (HAS). Clin Exp Dermatol.36 (7):715-723.

3. Wassef M, Blei F, Adams D, Alomari A, Baselga E, Berenstein A, et al. (2015) Vascular anomalies classification: Recommendations from the international society for the study of vascular anomalies Pediatrics.136 (1):e203-214.

4. Semkova K, Kazandjieva J, Kadurina M, Tsankov N. (2015) Hemangioma Activity and Severity Index (HASI), an instrument for evaluating infantile hemangioma: Development and preliminary validation. Int J Dermatol.54 (4):494-498.

5. Léauté-Labrèze C, Hoeger $\mathrm{P}$, Mazereeuw-Hautier J, Guibaud L, Baselga E, Posiunas G, et al. (2014) A randomized, controlled trial of oral propranolol in infantile hemangioma. $\mathrm{N}$ Engl J Med.372 (8):735-746.

6. Léaute-Labréze C, Boccara O, Degrugillier-Chopinet $\mathrm{C}$, Mazereeuw-Hautier J, Prey S, Lebbé G, et al. (2016) Safety of oral propranolol for the treatment of infantile hemangioma: A systematic review. Pediatric.138 (4).

7. Léauté-Labrèze C, Dumas de la Roque E, Hubiche T, Boralevi F. (2010) Propranolol for Hemangiomas of Infancy. N Engl J Med.2 (4):154-155.

8. Moyakine AV, Herwegen B, van der Vleuten CJM. (2017) Use of the Hemangioma Severity Scale to facilitate treatment decisions for infantile hemangiomas. J Am Acad Dermatol.77(5):868-873.

9. Mata Vicente JF. (2012) Escalas pronósticas en la Unidad de Terapia Intensiva. Rev Asoc Mexiacana Medicna.XXVI:234241.

10. Hechavarría-Toledo S. Los tipos de Escalas y ejemplos para su diseño [Internet]. 2019. p. 6. 